\title{
A EJA E A ESCOLA MUNICIPAL PROFESSORA MARIA ELVIRA NO MUNICÍPIO DE PONTA GROSSA
}

\author{
THE EJA AND MUNICIPAL SCHOOL TEACHER IN MARIA ELVIRA \\ PONTA GROSSA
}

\author{
Rita de Cássia Oliveira ${ }^{1}$ \\ Paola Andresssa Scortegagna ${ }^{2}$ \\ Flávia da Silva Oliveira ${ }^{3}$
}

\begin{abstract}
RESUMO
O contexto atual revela uma sociedade em constante movimento, com intensas mudanças sociais, políticas, econômicas e culturais, apresentando num ritmo acelerado novos desafios e possibilidades para a população. Nesta realidade, a educação se insere como um poderoso instrumento de modernização e avanço social. Diante disso, o presente trabalho objetiva uma reflexão sobre a educação de jovens e adultos (EJA) no Brasil, focando em especial a criação e implementação da EJA na Escola Municipal Professora Maria Elvira Justus Schimidt, a qual se encontra na zona rural do município de Ponta Grossa - Paraná. A pesquisa também tem como objetivo identificar o perfil dos alunos que frequentam essa modalidade de educação na referida escola. A investigação partiu de uma pesquisa bibliográfica, documental, descritiva e interpretativa. Como instrumentos foram utilizados questionários, os quais foram aplicados aos alunos da educação de jovens e adultos da escola pesquisada. Como resultado, constatou-se que os alunos entrevistados têm consciência da importância que o conhecimento sistemático possui em suas vidas e também em seu trabalho, possibilitando a melhoria das condições de ascensão na carreira ou a busca de uma melhor oportunidade. Apesar de todas as dificuldades enfrentadas por esses alunos, percebe-se sua perseverança em procurar uma escola e continuar a trajetória estudantil, um dia interrompida por diversos fatores. Comprova-se, então, que os alunos da EJA possuem grande interesse pelos estudos, visualizando a possibilidade de superação das dificuldades e adversidades por meio da educação. Percebe-se que a EJA constitui uma modalidade de educação cada vez mais reconhecida socialmente e considerada pelos alunos como possibilidade de resgate da cidadania e ascensão social e profissional.
\end{abstract}

Palavras-chave: Educação de jovens e adultos. Educação permanente. Política educacional.

\footnotetext{
${ }^{1}$ Doutora em Educação. Professora Associada e Professora Permanente do Departamento de Educação e do Mestrado em Educação da Universidade Estadual de Ponta Grossa. Coordenadora da Universidade Aberta para a Terceira Idade. E-mail: soliveira13@uol.com.br

${ }^{2}$ Pedagoga. Mestre em Educação. Professora da Universidade Aberta para a Terceira Idade, na UEPG.

${ }^{3}$ Bacharel em Direito. Mestre em Ciências Sociais Aplicadas. Coordenadora e Professora do Curso de Direito da Faculdade União. Professora da Universidade Aberta para a Terceira Idade, na UEPG.
} 


\begin{abstract}
Society in constant movement with intense social, political, economic and cultural changes, posing fast-paced new challenges and opportunities for the population. In this context, education is understood as a powerful instrument of modernization and social progress. This paper reflects on the education of youth and adults (YAE, EJA in Portuguese) in Brazil, focusing in particular on the creation and implementation of the YAE at the Municipal School Professor Maria Elvira Justus Schmidt, located in the rural area of Ponta Grossa - Parana. The study also aimed to identify the profile of students involved this form in education. The investigation began with a literature review followed by a descriptive and interpretive document analysis. Questionnaires were applied to the students as a form of data collection. Results showed that the students interviewed are aware of the importance that systematic knowledge has on their lives and work, influencing the advancement in their careers or in the search of better opportunities. Despite the difficulties faced by these students, it is possible to observe their perseverance in continuing their studies, which have been interrupted by several factors. The study demonstrated that students have great interest in their studies as they view education as a possibility for overcoming hardship and adversity. It can be noticed that Youth and Adult Education is a form of education socially recognized and considered by students as a possibility for recovering citizenship, social and professional development.
\end{abstract}

Keywords: Youth and adults education. Permanent education. Educational policy.

\section{Contexto da EJA no brasil}

A identidade da Educação de Jovens e Adultos configura-se num âmbito ambíguo e muitas vezes contraditório, demonstrando a necessidade de uma organização na qual a população beneficiada com esse segmento educacional realmente atinja seus objetivos enquanto cidadãos em busca de novas oportunidades através da educação.

Esse segmento de ensino confronta-se com a necessidade de diminuição das elevadas taxas de analfabetismo existentes no Brasil, as quais apesar de apresentarem um decréscimo significativo nos últimos anos, principalmente na população jovem (IBGE), ainda estão longe de alcançar um índice aceitável de analfabetos, cumprindo os objetivos educacionais traçados pela Organização das Nações Unidas (UNESCO) para 2015.

A quantidade de alunos matriculados na Educação de Jovens e Adultos no Brasil representa um número significativo. Segundo o Censo Escolar de 2006, há 5.616.291 alunos matriculados nessa modalidade, em cursos presenciais e semipresenciais (MEC/INEP). Esse número representa um avanço significativo, em relação à oferta da EJA no Brasil.
No estado do Paraná os números também são muito expressivos, corroborando a movimentação que ocorre acerca da EJA em todo país. Os dados do Censo Escolar de 2006 indicam que 189.997 alunos estão matriculados na Educação de Jovens e Adultos no estado, nos cursos presenciais e semipresenciais (MEC/INEP).

Os referidos números mostram que a EJA está tornando-se uma modalidade que necessita de uma especificidade própria, uma vez que a quantidade de alunos nela matriculados vem crescendo consideravelmente nos últimos anos.

Apesar de os dados apresentados representarem um importante avanço quanto à quantidade de alunos matriculados em cursos presenciais, a realidade vivenciada aponta que a alfabetização e a EJA apresentam-se no governo como uma proposta relegada a um segundo plano, por meio de um caráter apenas qualitativo.

O Brasil é mais do que um país. É uma imensa região marcada por profundas assimetrias e desigualdades econômicas e sociais, regionais e étnicas, com um considerável e histórico atraso na construção da escola para todos. (TEODORO, 2003, p. 138). 
Nas sociedades capitalistas, a educação tem estado a serviço da manutenção dos privilégios de classe. A ideologia liberal, que dá sustentação ao sistema capitalista, coloca a questão em termos de diferenças individuais, atribuindo ao próprio indivíduo o seu sucesso ou fracasso social e escolar, omitindo os condicionantes de ordem social, histórica, política e econômica que levam algumas pessoas ao sucesso e outras à marginalização ou exclusão do sistema como um todo, legitimando a sociedade de classes.

É possível perceber que a escola tem contribuído para reforçar situações de preconceito em relação às camadas pobres, quando afirma que a educação trabalha apenas em nível das ideias e segue orientações e normas iguais para todos os alunos. Baseada em princípios individualizantes, acaba por rotular os indivíduos segundo seu aproveitamento, sem levar em conta as condições concretas de existência e o universo cultural dos alunos.

Os teóricos crítico-reprodutivistas (BOURDIEU, PASSERON, ALTHUSSER, 1970) criticam a escola de inspiração liberal, denunciam seu caráter classista e os mecanismos utilizados para perpetuar as desigualdades sociais.

A escola não distribui poder, mas constrói saber que é poder. Não se muda a história sem conhecimentos, mas tem-se que educar o conhecimento para que se possa interferir no mercado como sujeito, não como objeto. O papel da escola consiste em colocar o conhecimento nas mãos dos excluídos de forma crítica, porque a pobreza política produz pobreza econômica (GADOTTI, 1979).

A educação desponta como um instrumento indispensável para a formação desse novo homem e novo profissional, através do processo de socialização e integração, sendo possível desmistificar os choques culturais e sociais presentes em nossa sociedade. Assim, a população passa a exigir cada vez mais condições de acesso e permanência na escola, com uma educação de qualidade, proporcionando uma formação que contemple as suas necessidades e aspirações.

A EJA no Brasil configura-se, portanto, como necessidade para a população não-escolarizada, que busca, através da educação, superar suas mazelas sociais, sendo capaz de emergir no processo de qualificação tanto profissional quanto pessoal.

Essa modalidade vem ao encontro das classes sociais menos favorecidas, uma vez que o estado capitalista busca incessantemente o lucro exacerbado, sem preocupar-se com toda parcela da população que se encontra à margem desse contexto. Nestas condições, a educação apresenta-se como possibilidade de mudança dessa realidade vivenciada.

A EJA, no transcorrer do seu processo histórico, apresenta-se como uma educação compensatória (GADOTTI; ROMÃO, 2005), sendo vista como uma oportunidade para superar uma falha no processo educacional dos alunos inclusos nessa modalidade. Desta maneira, os beneficiados com a mesma buscam na educação as possibilidades de superar suas condições de trabalho e sobrevivência.

\section{A EJA na cidade de Ponta Grossa}

A Educação de Jovens e Adultos na cidade de Ponta Grossa apresenta alguns avanços em relação à própria história dessa modalidade. Porém, percebe-se que ainda há muito a se fazer. Num contexto mais amplo, nota-se que existem muitos fatores importantes que levam uma significativa parte dos alunos do ensino regular a se evadir do sistema de ensino. Em alguns casos, esses alunos retornam à escola, em busca principalmente de melhores condições de trabalho e elevação da autoestima. Enfim, eles estão buscando novas possibilidades de conclusão de seus estudos, para conseguirem um avanço social.

Na cidade de Ponta Grossa, a EJA configura-se como um espaço em construção, apesar de já há alguns anos fazer parte do contexto educacional da cidade, principalmente a partir dos anos 1990. Todavia, essa modalidade educacional é muitas vezes considerada aquém da Educação Básica.

Para a realização desta pesquisa, foram selecionadas as escolas rurais municipais, as quais atendem a demanda das séries iniciais do Ensino Fundamental. E, dentre essas escolas, foi selecionada a escola do distrito de Guaragi, devido à possibilidade de observação, interação com os alunos e aplicação dos questionários.

\section{A Escola Municipal Professora Maria Elvira Justus Schimidt}

A referida escola está situada no distrito de Guaragi, zona rural do município de Ponta Grossa/Paraná. Esse distrito fica a aproximadamente $25 \mathrm{~km}$ da cidade. Por ser uma escola municipal, tem como mantenedora a Secretaria Municipal de Educação (SME). 
A Escola Maria Elvira tem um histórico recente. Foi fundada em 1996, para atender a demanda local do distrito, e seu nome homenageia a professora que foi pioneira na educação nessa localidade.

Pelo fato de a escola encontrar-se na zona rural, além de atender a demanda do distrito, também atende alguns vilarejos vizinhos. Como a maioria dos alunos que moram nesses vilarejos é proveniente de fazendas que ficam afastadas da escola, o transporte escolar rural possibilita a eles o acesso a essa instituição escolar.

A escola tem aproximadamente 250 alunos, nas séries iniciais do Ensino Fundamental e na Educação de Jovens e Adultos. Há dez turmas, sendo uma de EJA, seis professoras, duas serventes, pedagoga, diretora, escriturária, merendeira e agente de segurança institucional.

\section{A EJA na Escola Maria Elvira}

A Educação de Jovens e Adultos começou a funcionar na Escola Municipal Professora Maria Elvira Justus Schimidt em data relativamente recente. A primeira turma desse estabelecimento iniciou em 2006, contando com 12 alunos matriculados. No ano seguinte (2007), o número de matriculados caiu para oito alunos. Em 2008, a escola teve uma turma de 16 alunos, no período vespertino. No ano de 2009, devido a alterações no calendário escolar, a aplicação e levantamento de dados dos questionários ainda se encontram em processo.

\section{Perfil dos alunos da EJA}

Para compreender qual é a identidade dos alunos que estão matriculados na Educação de Jovens e Adultos, é necessário estabelecer um perfil, tanto nos aspectos sociais quanto econômicos, para que se possa verificar qual é a realidade que esses alunos enfrentam.

Dos 16 alunos que frequentam a EJA na referida escola, oito responderam ao questionário. Isso não aconteceu com os demais alunos, porque não estavam presentes nos dias em que houve a aplicação desse instrumento de pesquisa. Como se trata de uma escola rural, em determinados períodos muitos alunos trabalham em atividades agrárias, o que justifica a sua ausência.

Em relação ao sexo, percebe-se que $75 \%$ dos alunos (percentual esse que corresponde a seis alunos) são mulheres, enquanto $25 \%$ do alunado (dois alunos) são homens, confirmando que a feminilidade na Educação de Jovens e Adultos está cada vez mais representativa.

Outro fator pesquisado refere-se à idade, que comprova a tendência atual da juvenização dessa modalidade de ensino. As idades dos alunos variam, sendo que 37,5\% deles (três alunos) têm entre 15 e 19 anos, seguidos por $25 \%$ (dois alunos) que estão na faixa etária de 25 a 30 anos, e por 37,5\% (três alunos) cuja idade é superior a 41 anos.

Em relação ao estado civil, pode-se observar que quatro alunos (os quais representam $50 \%$ do total) são solteiros e que um aluno (12,5\%) é casado. Há, também, um aluno viúvo (que representa $12,5 \%$ do total) e dois alunos (25\%) que moram com companheiro.

Acerca da quantidade de filhos, constatou-se que quatro alunos (representando $50 \%$, ou seja, a metade do alunado) não têm filhos; dois alunos (que correspondem a $25 \%$ do total) têm dois filhos; e outros dois alunos (que representam também 25\%) têm quatro filhos.

Com relação ao percentual das atividades que esses alunos costumam fazer nos momentos de folga ou lazer, pode-se apontar que 50\% deles, ou seja, quatro alunos visitam seus parentes, e outros $50 \%$ (também quatro alunos) costumam ir à igreja. Além de indicar essas atividades, um aluno (12,5\%) fica também com sua mãe; outro aluno (12,5\%) costuma assistir a programas de televisão; e outro $(12,5 \%)$ escuta música no tempo livre.

Analisando a questão da ocupação desses alunos, constata-se que cinco alunas são donas de casa, representando $62,5 \%$ da totalidade. Os demais alunos, ou seja, três alunos que representam $37,5 \%$ da sua turma, não trabalham. Sendo assim, não houve o registro de nenhuma profissão nas respostas dos alunos.

A partir dessa questão, verifica-se que seis alunos ( $75 \%$ do total) vivem com até um salário mínimo na renda familiar, seguidos por um aluno $(12,5 \%)$ que tem sua renda familiar entre um e dois salários mínimos, e por outro aluno (12,5\%) que não possui renda familiar.

Ao se considerar as questões de habitação, seis alunos - que correspondem ao percentual de $75 \%$ moram em casa própria, enquanto um aluno $(12,5 \%)$ mora em uma casa cedida. Outro aluno, que representa também 12,5\%, vive na Cidade dos Meninos, que é um abrigo para menores. Pode-se observar, a partir desses dados, que a maioria dos alunos tem casa 
própria. Ao se pensar no aluno proveniente do abrigo para menores, percebe-se a diferença de contextos e realidades dos alunos de uma sala de EJA.

Em relação aos locais onde os alunos moram, destaca-se outro ponto: cinco alunos, ou seja, $62,5 \%$ do total moram em casas de alvenaria, e os três alunos restantes $(37,5 \%)$ moram em casas de madeira.

Com relação à quantidade de pessoas que moram juntos na mesma casa, 37,5\% dos alunos (três alunos) têm em suas casas mais de cinco pessoas. Com o percentual de $25 \%$, dois alunos moram em casas habitadas por quatro pessoas. Os demais alunos vivem em casas habitados por duas, três e cinco pessoas.

Em relação aos dados escolares dos alunos pesquisados, sete alunos $(87,5 \%)$ já tinham frequentado o ensino regular em algum momento de suas vidas. Dentre eles, três alunos (que correspondem a 37,5\% do total) já haviam sido matriculados na própria Escola Maria Elvira. Apenas um aluno (que representa $12,5 \%$ do total) nunca havia sido matriculado, nem frequentado uma escola antes.

Acerca dos dados sobre a última vez em que esses alunos estiveram matriculados e cursaram alguma série, destaca-se que 50\% deles (quatro alunos) frequentaram a escola pela ultima vez quando eram crianças; $25 \%$ (dois alunos) sempre estiveram matriculados; $12,5 \%$ (um aluno) nunca tinha ido à escola; e outro aluno $(12,5 \%)$ não soube responder a questão.

Os alunos foram questionados sobre o desejo de continuar estudando após a EJA. Aponta-se que sete alunos (percentual referente a $87,5 \%$ da totalidade de alunos) desejam continuar estudando e apenas um aluno $(12,5 \%)$ não quer dar continuidade aos seus estudos. Dentre os alunos que desejam continuar estudando, três $(37,5 \%)$ não sabem ainda o que irão estudar; um aluno quer se formar num curso superior; outro aluno quer aprender tudo o que lhe for ensinado; e outro vai estudar somente se puder continuar fazendo isso durante o dia.

Apenas um aluno, representando $12,5 \%$ do total, tem um curso profissionalizante de costura; os demais alunos (sete), que correspondem a $87,5 \%$ da totalidade, nunca fizeram nenhum curso dessa natureza.

Ao se falar sobre os motivos que levaram os alunos pesquisados a parar seus estudos no ensino regular, $25 \%$ deles - percentual que corresponde a dois alunos - indicaram como motivo a multirrepetência; e um aluno, representando $12,5 \%$ do total, nunca parou de estudar. Os demais alunos (cinco) tiveram motivos particulares para sair da escola, enumerados a seguir: necessidade de ajudar em casa, cuidando dos irmãos; trabalho como babá de sobrinho; não ter condução para chegar à escola; ser tirado da escola pelo pai; e briga com zeladora da escola.

Apesar de terem parado de estudar, esses alunos resolveram retornar à escola para dar continuidade aos seus estudos, ou mesmo para iniciá-los. Pode-se destacar que três deles, representando $37,5 \%$ do total, estão na EJA para aprender; dois alunos, correspondendo a $25 \%$, estão na EJA por causa da multirrepetência. Para um aluno a EJA é uma oportunidade; para outro, o motivo principal para estar na EJAé a coragem, pois sempre teve vontade para aprender. Um último aluno que respondeu ao questionário colocou que o motivo para estar na EJA e estudar é que seus filhos estão na escola e ele deseja aprender para poder ajudá-los.

Como esses alunos estão dando continuidade aos seus estudos, foram questionados sobre qual horário utilizam para estudar em casa. A maioria, ou seja, seis alunos, representados por $87,5 \%$ do total de alunos, estudam após o horário da aula; um aluno, correspondendo a $12,5 \%$, estuda antes de ir à escola; e outro aluno, representando também $12,5 \%$, não tem horário para estudar em casa.

Quando iniciaram seus estudos na EJA, seis alunos (número que corresponde a $75 \%$ do total) não eram alfabetizados e, representando $25 \%$ desse total, dois alunos já estavam no nível fundamental. No momento atual, todos os alunos estão no nível fundamental. Com os percentuais de $50 \%$ (quatro alunos) e $62,5 \%$ (cinco alunos), respectivamente, eles buscam notícias no rádio e na televisão.

Apenas um aluno, correspondendo a 12,5\%, participa de uma associação, a Associação de Moradores da localidade.

Percebe-se que a EJA surge como uma esperança e possibilidade para que muitos alunos que hoje estão nela inseridos alcancem novos objetivos e tenham outras perspectivas de futuro, com melhores condições de trabalho, as quais repercutem diretamente na qualidade de vida, participação social e busca por direitos.

Segundo Freire (2005), ao ligar-se a Educação de Jovens e Adultos a uma das tendências da moderna concepção progressista, é necessário tornar essa mo- 
dalidade de educação acessível às camadas populares. Porém, a educação só cumprirá seu caráter político e social na medida em que se possa criar o espaço de discussão e problematização da realidade, com vistas à educação consciente, voltada para o exercício da cidadania por sujeitos comprometidos com a transformação da realidade, envolvendo jovens, adultos e idosos, nas mais diversas dimensões.

Um regime político democrático exige que as pessoas tenham domínio de instrumentos da cultura letrada, que assumam valores e atitudes democráticas: a consciência de direitos e deveres, a disposição para a participação, para o debate de ideias e o reconhecimento de posições diferentes das suas.

O Brasil vem reconstruindo as instituições democráticas e, nesse processo, a educação tem um papel a cumprir com relação à consolidação da democracia em nosso país. Assim, cabe à educação estabelecer uma relação democrática entre a política e os sujeitos deste paradoxo educacional, a fim de reordenar e reconstruir gradativamente um processo ensino-aprendizagem pautado na construção e reconstrução crítica, reflexiva e democrática dos conhecimentos, na qual todos os indivíduos presentes nesse meio possam desenvolver-se e constituírem-se como cidadãos atuantes e conscientes.

\section{Considerações finais}

Pode-se concluir que a EJA na cidade de Ponta Grossa já evoluiu significativamente nos últimos anos, considerando-se que o número de alunos atendidos vem aumentando. Todavia, ainda são necessárias políticas públicas especificas, que atendam a essa modalidade de ensino propiciando uma educação de qualidade para jovens, adultos e idosos que não tiveram a oportunidade, ou condições, de frequentar a escola no período regular.

Também, faz-se necessário uma política nos âmbitos Federal, Estadual e Municipal, que viabilize recursos para que seja realizado um trabalho de melhor qualidade. O estudo, a pesquisa e a produção de material didático-pedagógico são importantes para a realização desse trabalho.

Superar todo esse contexto no qual se construiu a Educação de Jovens e Adultos que se apresenta hoje não é fácil. É preciso, antes de tudo, entender a escolarização desses alunos como de fundamental importância, pois eles são os pais, as mães, os trabalhadores, aqueles que constroem, com seu trabalho, os meios necessários à sobrevivência e que na história deixam a sua contribuição.

A superação do quadro crônico de analfabetos ou semianalfabetos em nosso país está a exigir o repensar dessa importante questão recorrente no processo de nosso desenvolvimento histórico, sendo necessário promover debates acadêmicos, elaborar e desenvolver pesquisas e propostas que visem a superar a situação de extrema desigualdade social e educacional vigentes no contexto brasileiro.

Di Pierro, Jóia e Ribeiro (2001) consideram que os governos precisam assumir mais claramente uma atitude convocatória, chamando toda a sociedade a engajar-se em iniciativas voltadas à elevação do nível educativo da população. O teor desse chamado deve contemplar, especialmente, a motivação para que todos continuem aprendendo ao longo da vida, visto que a necessidade, a vontade e a possibilidade de aprender são inerentes a todos os seres humanos, do nascimento à velhice. É preciso considerar, também, a necessidade de qualificar a demanda por esses serviços, por meio de ações culturais e políticas voltadas ao amplo reconhecimento do valor da educação continuada como estratégia de promoção de equidade educativa e social.

Percebe-se, portanto, que a Educação de Jovens e Adultos apresenta-se como questão ampla e complexa, que não será resolvida apenas em nível de decisões governamentais, mas exige o engajamento de todas as pessoas que acreditam no potencial humanizador e transformador da educação, oportunizando a inserção crítica e participativa de seus usuários nos destinos da sociedade.

\section{REFERÊNCIAS}

BRASIL. Censo escolar. Brasília: MEC/INEP, 2008.

DI PERRO, M.C.; JÓIA, O.; RIBEIRO, V. M. Visões da educação de jovens e adultos no Brasil. Disponível em: http:/www.scielo.br/pdf/ccedes. Acesso em: 20 nov. 2005.

FREIRE, P. Pedagogia do oprimido. 45. ed. São Paulo: Paz e Terra, 2005.

GADOTTI, M. Educação e ordem classista. Rio de Janeiro: Cortez, 1979. 
GADOTTI, M; ROMÃO J. E. Educação de jovens e adultos: teoria, prática e proposta. 2 ed. São Paulo: Cortez, 2005.

INAF. Indicador de analfabetismo funcional. São Paulo: Instituto Paulo Montenegro/IBOPE, 2007.

TEODORO, A. Globalização e educação: políticas educacionais e novos modos de governação. São Paulo: Cortez, 2003. 